\title{
Impact of Presurgical Nasoalveolar Molding on the Parental Perceptions of Oral Health-related Quality of Life of Children with Cleft Lip and Palate
}

\author{
Fahad N AlAnazi ${ }^{1}$, Wasmiya A AlHayyan ${ }^{2}$, Sharat C Pani ${ }^{3}$
}

\begin{abstract}
Aim: The study aimed to examine the oral health-related quality of life (OHRQoL) of children with cleft lip and palate who were treated with presurgical nasoalveolar molding (PNAM) and to compare the results to age- and gender-matched controls without cleft lip and palate.

Materials and methods: Parents of 51 children with cleft lip and palate who were treated with PNAM were administered a validated Arabic version of the short-form child oral health impact profile (COHIP-SF) and were asked to rate their experience with PNAM. The children with treated cleft lip and palate (study group) were age- and gender-matched to children with no cleft lip and palate (control group). The differences in COHIP-SF domains were compared between groups using the Mann-Whitney $U$ test.

Results: The children in the test group had significantly higher COHIP-SF scores than in the test group $(p<0.001)$. However, there were no significant differences in the oral health $(p=0.532)$ or the oral function $(0.232)$ domains. There were, however, significant differences in the socioemotional domain $(p<0.001)$. Most of the parents $(86 \%)$ of children with cleft lip or palate felt that they would recommend PNAM to other parents.

Conclusion: While there are no differences in the oral health and functional domains of OHRQoL, children with cleft lip and palate treated with PNAM have significantly lower scores in the socioemotional domain of OHRQoL when compared to age- and gender-matched controls. Clinical significance: Presurgical nasoalveolar molding does not have any negative impact on the OHRQoL of children with cleft lip and palate. Keywords: Cleft lip and palate, Oral health-related quality of life, Presurgical nasoalveolar molding.

The Journal of Contemporary Dental Practice (2020): 10.5005/jp-journals-10024-2761
\end{abstract}

\section{INTRODUCTION}

According to the World Health Organization (WHO) database, congenital anomalies are a major cause of mortality and morbidity during childhood, affecting $2-3 \%$ of all infants. ${ }^{1}$ Oral clefts are twice as common as other congenital anomalies in the United States. ${ }^{2}$

Cleft nasal cartilage molding was first described by Matsuo et al. and Matsuo and Hirose. ${ }^{3,4}$ In 1993 Grayson and Wood designed a presurgical orthopedic appliance that sought to mold the alveolus, lip nose of newborn patients with cleft lip and palate prior to surgical repair. ${ }^{5}$ This approach has been adopted world over as nasoalveolar molding or presurgical nasoalveolar molding (PNAM). ${ }^{6}$ Benefits of this technique include nasal symmetry after lip and palate closure surgery, ${ }^{1,7}$ and reduction in the number of surgical revisions of excessive scaring, oronasal fistula, and nasal and labial deformities $^{6,8}$ and improvement of maxillary dental arch shape. ${ }^{9,10}$ However, despite the many reported advantages, this technique is time consuming, is expensive and requires parental compliance. ${ }^{1}$ These factors have meant that PNAM is not universally practiced in all cleft centers. ${ }^{8}$

Oral health-related quality of life $(\mathrm{OHRQ} \mathrm{L})$ is a personal evaluation of oral health, emotional welfare, functional welfare, expectations, fears, and care satisfaction through a multidimensional survey. ${ }^{11}$ There have been several attempts to use parental questionnaires to examine the OHRQoL of children with cleft lip and palate, both before and after the surgery. ${ }^{12-15}$ However, there are no data on the impact that PNAM can have on the QHRQoL. There has also been no attempt made to understand the impact of PNAM on the OHRQoL of children with cleft lip and palate. The child oral health impact scale-short form (COHIP-SF) is a validated measure that seeks to determine the perception of a child's OHRQoL
${ }^{1}$ Department of Preventive Dental Sciences, Riyadh Elm University, Riyadh, Kingdom of Saudi Arabia

${ }^{2}$ Department of Dentistry, Ministry of Health, Kuwait

${ }^{3}$ Department of Paediatric Dentistry, Western University, Schulich School of Medicine and Dentistry, London, Ontario, Canada

Corresponding Author: Sharat C Pani, Department of Paediatric Dentistry, Western University, Schulich School of Medicine and Dentistry, London, Ontario, Canada, Phone: +1 4372411679, e-mail: Sharat.pani@gmail.com

How to cite this article: AlAnazi FN, AlHayyan WA, Pani SC. Impact of Presurgical Nasoalveolar Molding on the Parental Perceptions of Oral Health-related Quality of Life of Children with Cleft Lip and Palate. J Contemp Dent Pract 2020;21(2):152-155.

Source of support: Nil

Conflict of interest: None

through 19 questions in three major domains. ${ }^{16}$ The questionnaire has been recently validated in Arabic. ${ }^{16}$

This study aimed to assess the OHRQoL of children aged below 5 years of age who had cleft lip and palate who were undergoing nasoalveolar molding prior to surgery and compare these to ageand gender-matched controls using the validated Arabic version of the COHIP-SF.

\section{Materials and Methods Ethical Approval}

The proposal was registered with the research center of the Riyadh Elm University and ethical approval was obtained from 
the Institutional Review Board of the Riyadh Elm University (RC/IRB/2019/86). Informed consent was obtained from the parents of all children before interviewing them.

\section{Source of Patients}

The sample of parents of children who received PNAM prior to cleft surgery was selected from the records of the AIAmeri Hospital Kuwait City, Kuwait. Parents were age- and gender-matched to ensure a similar demographic profile with a similar age of child. The sample for the control parents was obtained from the medical records of the Riyadh Elm University.

\section{Sample Power Calculation}

Given the relative rareness of the condition, all patients reporting to the center for surgery were included in the sample. We were able to obtain information from the parents (either mother or father) of 51 children with cleft lip and palate treated with PNAM and matched them to 51 sets of control parents. The post hoc power of the described sample (with an effect size of 0.8 and $a$ of 0.05 ) was 0.96 .

\section{Recording of OHRQoL}

Parental perception of the OHRQoLwas recorded using the validated Arabic version of the child oral health impact profile-short form (COHIP-19). ${ }^{16}$ In addition to the questionnaire, a general question regarding the parents' overall experience with nasoalveolar molding was added for the group with cleft lip and palate.

\section{Statistical Analyses}

The $t$ test was used to compare age differences between groups and genders, while the Mann-Whitney $U$ test was used to compare differences in the OHRQoL between groups. All statistics were performed using SPSS ver. 23 data processing software (IBM SPSS, IBM Corp. Armonk, NY, USA).

\section{Results}

The sample comprised of 51 ( 27 fathers and 24 mothers) parents of children aged between 5 years and 11 years. The children ( 26 male and 25 female) were aged between 6 years and 11 years (mean age 7.15 years, \pm SD 2.02 years) at the time of the parental interview. The males were (mean age 6.75 years, SD \pm 2.1 years) slightly younger than the females (mean age 7.54 years, $S D \pm 1.87$ years); however the $t$ test showed that the difference was not statistically significant ( $t=-2.345, p=0.051)$. All children had been operated on for cleft lip at the age of between 3 months and 4 months and secondary palate surgery at the age of between 9 months and 15 months.
The control group was matched for age and gender of the child as well as type of respondent (father or mother). It was observed that there was no significant difference in the economic profile of the cleft and control group (Table 1).

When the overall COHIP-SF were compared between the cleft and control groups, it was observed that the parents of children with cleft showed significantly higher scores than the parents in the control group. However, when the scores were compared according to domain, it was observed that there was no significant difference in the oral health and oral function domains (Table 2). The only domain to show a significant difference $(p<0.001)$ was the socioemotional domain (Table 2).

Among the children with cleft, it was observed that the parents of girls reported higher COHIP-SF scores than the parents of boys. The differences were, however, not statistically significant (Table 3). When the parents were asked about their overall opinion of their experience with PNAM, most of the parents reported that they had faced problems during the phase of placement of the appliance but that they would recommend the use of the appliance to other parents $(n=29), 15$ parents reported having faced no problems during the placement of the appliance, and only 7 parents stated that they found no benefit from the appliance and would not recommend it to other parents (Fig. 1).

\section{Discussion}

Oral health-related quality of life of patients with cleft lip and palate has been receiving attention in the recent literature. ${ }^{13-15}$ In spite of literature showing that over $60 \%$ of centers across the world use PNAM, ${ }^{8}$ little is known about its impact on the OHRQoL of children with cleft lip and palate. This paper aimed to address the gap in literature.

Oral health-related quality of life is a subjective measure and it is important to ensure that the population being measured is somewhat homogenous in order to reduce unintentional bias. ${ }^{17}$ It was for this reason the cleft population surveyed in this study was from a single center, rather than multiple centers. However, since the use of PNAM is mandatory in the center studied, we were unable to recruit a group of children who had undergone surgery for cleft lip and palate without the use of PNAM.

The role of oral health and oral function in OHRQoL is well established. ${ }^{17-19}$ The fact that our study found no significant differences between the cleft and control groups in these domains is in keeping with the findings of other studies. This is attributed to the fact that while cleft lip and palate does cause dental anomalies such as missing or malformed teeth, they do not appear to affect oral health or oral function. ${ }^{13-15}$

Table 1: Economic profile of the sample group parents

\begin{tabular}{|c|c|c|c|c|c|c|c|}
\hline & & \multicolumn{4}{|c|}{ Group } & \multirow[b]{3}{*}{ Mann-Whitney U } & \multirow[b]{3}{*}{ Sig. ${ }^{*}$} \\
\hline & & \multicolumn{2}{|c|}{ Control } & \multicolumn{2}{|c|}{ Cleft } & & \\
\hline & & Count & $\%$ & Count & $\%$ & & \\
\hline \multirow{5}{*}{$\begin{array}{l}\text { Monthly income } \\
\text { of family }\end{array}$} & $<300 \mathrm{KD} /$ month & 5 & 9.8 & 9 & 17.6 & 1058.5 & 0.098 \\
\hline & $301-500 \mathrm{KD}$ & 8 & 15.7 & 1 & 2.0 & & \\
\hline & $501-1,001 \mathrm{KD}$ & 19 & 37.3 & 11 & 21.6 & & \\
\hline & $1,001-2,000 \mathrm{KD}$ & 12 & 23.5 & 17 & 33.3 & & \\
\hline & $>2,000 \mathrm{KD}$ & 7 & 13.7 & 13 & 25.5 & & \\
\hline
\end{tabular}

*Differences are not statistically significant 
Table 2: Differences in the different domains of the short-form child oral health impact profile between cleft and control groups

\begin{tabular}{|c|c|c|c|c|c|c|c|c|}
\hline & \multicolumn{3}{|c|}{ Control } & \multicolumn{3}{|c|}{ Cleft } & \multirow[b]{2}{*}{ Mann-Whitney U } & \multirow[b]{2}{*}{ Sig. } \\
\hline & Mean & $\begin{array}{l}\text { Standard } \\
\text { deviation }\end{array}$ & Range & Mean & $\begin{array}{l}\text { Standard } \\
\text { deviation }\end{array}$ & Range & & \\
\hline Oral health domain & 11.51 & 2.31 & 9.00 & 11.22 & 2.87 & 13.00 & 1208.00 & 0.532 \\
\hline Function domain & 9.69 & 4.04 & 25.00 & 10.06 & 3.38 & 14.00 & 1145.00 & 0.232 \\
\hline $\begin{array}{l}\text { Socioemotional } \\
\text { domain }\end{array}$ & 23.43 & 3.96 & 16.00 & 30.29 & 4.56 & 25.00 & 346.00 & $<0.001^{*}$ \\
\hline COHIP-SF & 44.63 & 7.89 & 38.00 & 51.57 & 7.19 & 38.00 & 547.00 & $<0.001^{*}$ \\
\hline
\end{tabular}

*Differences are significant at $p<0.05$

Table 3: Gender differences in the short-form child oral health impact profile domains in the cleft group

\begin{tabular}{|c|c|c|c|c|c|c|c|c|}
\hline & \multicolumn{3}{|c|}{ Male } & \multicolumn{3}{|c|}{ Female } & \multirow[b]{2}{*}{ Mann-Whitney U } & \multirow[b]{2}{*}{ Sig. ${ }^{*}$} \\
\hline & Mean & $\begin{array}{l}\text { Standard } \\
\text { deviation }\end{array}$ & Range & Mean & $\begin{array}{l}\text { Standard } \\
\text { deviation }\end{array}$ & Range & & \\
\hline Oral health domain & 11.09 & 2.99 & 12.00 & 11.31 & 2.83 & 12.00 & 300.50 & 0.723 \\
\hline Function domain & 9.86 & 3.36 & 14.00 & 10.21 & 3.45 & 13.00 & 293.50 & 0.625 \\
\hline $\begin{array}{l}\text { Socioemotional } \\
\text { domain }\end{array}$ & 29.00 & 5.36 & 25.00 & 31.28 & 3.63 & 18.00 & 221.00 & 0.061 \\
\hline COHIP-SF & 49.95 & 8.43 & 38.00 & 52.79 & 5.95 & 21.00 & 233.00 & 0.101 \\
\hline
\end{tabular}

*Differences are not statistically significant

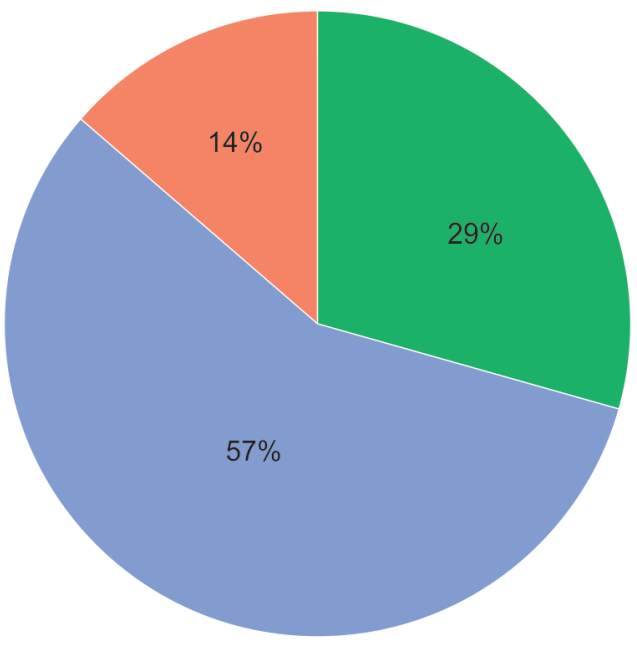

Had no problems and would recommend it Had problems, but would recommend it Would not recommend it and found no benefit

Fig. 1: Parental perception of nasoalveolar molding

There are several scales to measure the OHRQoL of children, and many of them such as the parental perception questionnaire (PPQ) or the early childhood oral health impact scale (ECOHIS) are filled by the parent and have been successfully validated in Arabic. ${ }^{17,19,20}$ Our decision to use the COHIP-SF, a relatively new scale, was based on the elaborate nature of the social and emotional impacts studied in the scale. ${ }^{16}$ Furthermore, the COHIP-SF also combines the social and emotional domains into one comprehensive domain. ${ }^{16}$ The significant difference in the socioemotional domain observed between the cleft and control children not only highlights the emotional impact of cleft lip and palate, but also suggests that the COHIP-SF may be a more useful tool in the study of children with oral clefts.

The use of PNAM has been associated with multiple compliance issues such as parental cooperation, development of rash in the child due to adhesive tapes, and in rare cases allergies to either the tape or the acrylic. ${ }^{1,6,8}$ However, the overall perception reported in this study was that only $11 \%$ of the parents felt that these problems were a barrier to the use of PNAM. This lends credence to the fact that OHRQoL is a complex dynamics where parents would be willing to look beyond the inconvenience caused by PNAM if they perceived the benefits to exceed the harm. It is important to remember that the parents surveyed in this study were surveyed between 2 years and 4 years after the final cleft surgery. The issue of memory recall bias has been raised by investigators looking into OHRQoL. Multiple studies have shown that the validation process of modern OHRQoL scales have sufficient validity to overcome memory recall bias. ${ }^{13,16,19}$

Traditional studies on the quality of life have focused on the overall health-related quality of life. In this regard the current study is an important addition to the literature as it attempts to assess the impact of a single procedure (PNAM) on the OHRQoL of children with cleft lip and palate. The finding that there were no significant differences between the test group and control group in the oral health and oral function domains. This is in keeping with the findings of authors who show that surgical closure of oral clefts often restores oral health and function to acceptable levels. ${ }^{11-13}$ In contrast there was a significant difference in the social domain of the scale between the cleft and control groups. This finding is interesting as it suggests that the restoration of oral health and oral function alone is not sufficient to overcome the social and emotional challenges of cleft lip and palate. This finding has been observed previously in studies both on children who have received PNAM prior to surgery and on those who have received no presurgical orthodontic treatment. ${ }^{7,8,10}$

The current study should be viewed keeping in mind certain limitations. The greatest limitation of the study is the fact that the OHRQoL of the test group was only compared to children who were free of cleft rather than children with cleft lip and palate who had not undergone PNAM. However, in spite of this limitation, the results of the current study show that most of the parents had a positive attitude toward PNAM. 


\section{Conclusion}

Within the limitations of the study it was concluded that while children with cleft lip and palate who had undergone PNAM had no significant difference in the oral health and functional components of OHRQoL, they had a significantly lower socioemotional component of quality of life than age- and gender-matched controls without cleft lip and palate.

\section{References}

1. Ezzat CF, Chavarria C, Teichgraeber JF, et al. Presurgical nasoalveolar molding therapy for the treatment of unilateral cleft lip and palate: a preliminary study. Cleft Palate Craniofac J 2007;44(1):8-12. DOI: 10.1597/06-009.

2. Mossey PA, Catilla EE, Global registry and database on craniofacial anomalies: Report of a WHO Registry Meeting on Craniofacial Anomalies; 2003.

3. Matsuo K, Hirose T, Otagiri T, et al. Repair of cleft lip with nonsurgical correction of nasal deformity in the early neonatal period. Plast Reconstr Surg 1989;83(1):25-31. DOI: 10.1097/00006534-19890100000006.

4. Matsuo K, Hirose T.Preoperative non-surgical over-correction of cleft lip nasal deformity. Br J Plast Surg 1991;44(1):5-11. DOI: 10.1016/00071226(91)90168-J.

5. Grayson BH, Wood R. Preoperative columella lengthening in bilateral cleft lip and palate. Plast Reconstr Surg 1993;92(7):1422-1423.

6. Grayson $\mathrm{BH}$, Cutting CB. Presurgical nasoalveolar orthopedic molding in primary correction of the nose, lip, and alveolus of infants born with unilateral and bilateral clefts. Cleft Palate Craniofac J 2001;38(3): 193-198.DOI: 10.1597/1545-1569_2001_038_0193_pnomip_2.0.co_2.

7. Keçik D, Enacar A. Effects of nasoalveolar molding therapy on nasal and alveolar morphology in unilateral cleft lip and palate. J Craniofac Surg 2009;20(6):2075-2080. DOI: 10.1097/SCS.0b013e3181be88cf.

8. Murthy PS, Deshmukh S, Bhagyalakshmi A, et al. Pre surgical nasoalveolar molding: changing paradigms in early cleft lip and palate rehabilitation. J Int Oral Health 2013;5(2):70-80.

9. Cho BC. Unilateral complete cleft lip and palate repair using lip adhesion combined with a passive intraoral alveolar molding appliance: surgical results and the effect on the maxillary alveolar arch. Plast Reconstr Surg 2006;117(5):1510-1529. DOI: 10.1097/01. prs.0000209467.98050.20.
10. Ruíz-Escolano MG, Martínez-Plaza A, Fernández-Valadés $R$, et al. Nasoalveolar molding therapy for the treatment of unilateral cleft lip and palate improves nasal symmetry and maxillary alveolar dimensions. J Craniofac Surg 2016;27(8):1978-1982. DOI: 10.1097/ SCS.0000000000003047.

11. Lamb CE, Whelan AK, Michaels C. Refugees and oral health: lessons learned from stories of Hazara refugees. Aust Health Rev 2009;33(4):618-627. DOI: 10.1071/AH090618.

12. Abebe $M E$, Deressa $W$, Oladugba $V$, et al. Oral health-related quality of life of children born with orofacial clefts in Ethiopia and their parents. Cleft Palate Craniofac J 2018; 1055665618760619. DOI: 10.1177/1055665618760619.

13. Naros A, Brocks A, Kluba S, et al. Health-related quality of life in cleft lip and/or palate patients - a cross-sectional study from preschool age until adolescence. J Craniomaxillofac Surg 2018;46(10):1758-1763. DOI: 10.1016/j.jcms.2018.07.004.

14. Rando GM, Jorge PK, Vitor LLR, et al. Oral health-related quality of life of children with oral clefts and their families. J Appl Oral Sci 2018;26:e20170106. DOI: 10.1590/1678-7757-2017-0106.

15. Zeraatkar M, Ajami S, Nadjmi N, et al. Impact of oral clefts on the oral health-related quality of life of preschool children and their parents. Niger J Clin Pract 2018;21(9):1158-1163. DOI: 10.4103/njcp. njcp_426_17.

16. Arheiam AA, Baker SR, Ballo L, et al. The development and psychometric properties of the Arabic version of the child oral health impact profile-short form (COHIP-SF 19). Health Qual Life Outcomes 2017;15(1):218. DOI: 10.1186/s12955-017-0796-4.

17. Pani SC, Badea L, Mirza S, et al. Differences in perceptions of early childhood oral health-related quality of life between fathers and mothers in Saudi Arabia. Int J Paediatr Dent 2012;22(4):244-249. DOI: 10.1111/j.1365-263X.2011.01185.x.

18. Emeka Cl, Adeyemo WL. A comparative study of quality of life of families with children born with cleft lip and/or palate before and after surgical treatment. J Korean Assoc Oral Maxillofac Surg 2017;43(4):247-255. DOI: 10.5125/jkaoms.2017.43.4.247.

19. Farsi NJ, El-Housseiny AA, Farsi DJ, et al. Validation of the Arabic version of the early childhood oral health impact scale (ECOHIS). BMC Oral Health 2017;17(1):60. DOI: 10.1186/s12903-017-0353-x.

20. Farsi DJ, Farsi NJ, El-Housseiny AA, et al. Responsiveness of the Arabic version of the ECOHIS to dental rehabilitation under general anaesthesia. Int J Paediatr Dent 2018;28(1):52-61. DOI: 10.1111/ ipd.12307. 